\title{
Ideal Fertility in Iran: A Systematic Review and Meta-analysis
}

\author{
Hajiieh Bibi Razeghi Nasrabad ${ }^{* \mathbb{D}}$, Mohammad Jalal Abbasi-Shavazi $^{2}$
}

\begin{abstract}
Objectives: This study was conducted to estimate the mean ideal number of children and to determine the overall prevalence of childlessness, one child, two children, as well as three children and more as the ideal number of children in Iran. Further, the study investigated the effect size of the relationship between social factors and ideal fertility.

Materials and Methods: To this end, a systematic review and meta-analysis was conducted on all studies on ideal fertility that were published from January 2000 to February 2018. Totally, 37 qualified papers and two national surveys were selected with a total sample size of 37,079 women. The degree of correlation between the ideal fertility and variables was calculated using Spearman's correlation, Pearson's correlation coefficient, and $\mathrm{r}$ by using MedCalc 17 software.

Results: The pooled mean ideal fertility by the random effect was 2.25 in Iran. The results of the Cochran test and I 2 statistics showed considerable heterogeneity regarding the prevalence of the ideal number of children $\left(\mathrm{Q}=1722.0911, P<0.0001\right.$, and $\left.\mathrm{I}^{2}=97.62 \%\right)$. In addition, the proportions of childlessness, 1 child, 2 children, along with 3 children and more as the ideal parity were $0.83,15.99$, 56.092 , and 22.26, respectively. The pooled correlation coefficients demonstrated that age, actual fertility, and the economic costs of children are the most important predictors of ideal fertility.

Conclusions: Despite the differences in the actual fertility level in different regions of Iran, two children is the the predominant pattern of the number of desired children. This result implies a convergence of fertility ideals in Iran. If desirable conditions for childbearing are provided, fertility could be maintained at the replacement level.

Keywords: Ideal fertility, Preference, Fertility, Meta-analysis, Pooled correlation, Iran
\end{abstract}

\section{Introduction}

Iran has experienced a dramatic fertility decline in recent decades. The total fertility rate decreased from 7.7 in 1966 to 1.8 in 2011 (1). In fact, over three decades (the 1980s-2000s), Iran has transformed from a high-fertility country to a low-fertility one.

Based on the report regarding the provincial-level fertility in 2011, the total fertility rate in 22 out of the 31 provinces of Iran was below the replacement level (2). Currently, rising fertility to above replacement level has become the main concern of demographers and policymakers in Iran.

There is evidence of a change in family-related behaviors in many parts of the world $(3,4)$, suggesting that changing attitudes about family life plays a crucial role in demographic changes $(5,6)$. Fertility ideals are considered as an important dimension of attained fertility. Although ideal parity is not an accurate predictor of completed fertility, it has an important role in identifying the fertility process.

In recent years, fertility intentions and ideals, as part of the reproductive decision-making process, have become important for gaining insight into future changes in actual fertility levels. Therefore, this paper aimed to examine women's fertility ideal in Iran. This gives rise to the consideration of how childbearing attitudes have changed in Iran in recent decades and how Iranians have perceived the ideal family size.

As far as data on ideal fertility ideals is concerned, DHS (Demographic and Health Surveys) data includes questions about fertility preferences, but this data on fertility preferences are used for evaluating various aspects of family planning programs and estimating unwanted fertility. More precisely, the lack of questioning the respondents about their fertility ideal was one of the important shortcomings of the national study of fertility in Iran.

Some empirical studies examined several aspects of fertility preferences in Iran. Although these studies provide valuable information on fertility preferences in one special population, they do not offer an understanding of the dynamics of fertility preferences. In addition, they tend to focus on women's perspectives at the city level or a particular region and ethnic group. Further, most of these studies are published in Persian demographic journals. To expand the knowledge on ideal family size in Iran,

Received 4 December 2018, Accepted 23 March 2019, Available online 29 March 2019

${ }^{1}$ National Population Studies and Comprehensive Management Institute, Iran. ${ }^{2}$ Department of Demography, Faculty of Social Sciences, University of Tehran, Tehran, Iran; \& Melbourne School of Population and Global Health, University of Melbourne, Melbourne, Australia.

*Corresponding Author: Hajiieh Bibi Razeghi Nasrabad, Email: hajiieh.razeghi@psri.ac.ir 
the present study reviewed relevant literature on fertility ideals found in Persian and English electronic databases. Accordingly, a systematic review and meta-analysis was performed on all published studies (from January 2000 to February 2018) to estimate the mean ideal number of children, as well as an overall prevalence of childlessness, one child, two children, and three children and more as the ideal number of children in Iran. In the meta-analysis, the sample size increases due to the combination of studies, thus it provides better statistical results (7). Meta-analysis can also extract the observed heterogeneity among the results of separate studies (8).

This study is important because it provides evidence on the ideal fertility in Iran. To the best of our knowledge, it is also the first study to examine the ideal fertility by metaanalysis. The awareness of couples' fertility preferences and ideals would provide evidence for designing relevant policies to increase fertility and/or at least to stop further fertility decline.

\section{Materials and Methods}

A systematic review and meta-analysis of all published studies was conducted to estimate the mean ideal number of children. The overall prevalence of childlessness, 1 child, 2 children, and 3 children and more as the ideal number of children in Iran was evaluated as well. For this purpose, a search of all published literature (from 2000 until February 2018) on the ideal number of children was conducted using Persian and English electronic databases such as Web of Science, PubMed, Scopus, Google Scholar, as well as national electronic databases such as SID, Magiran, and NOORMAGS. The Persian and English keywords and the possible combination of basic words were probed in this search. The study was conducted using keywords such as "ideal fertility", "desired fertility", "fertility preferences", "Iran/Iranian", along with the name of the provinces. The Farsi keywords were equivalent to their English word and all possible combinations were searched as well. This search was conducted during 2017-2018

In the first phase, 58 studies were found, including published articles, student theses, research projects, and more, followed by extracting the entire text or a summary of all searched articles, documents, and reports. The full-texts of relevant articles and national surveys were carefully studied after reviewing and studying the titles of documents and removing irrelevant articles. Finally, all Persian and English studies were included, which estimated the mean ideal number of children, as well as an overall prevalence of childlessness, 1 child, 2 children, and 3 children and more as the ideal number of children among women in Iran while articles, documents, and reports that were conducted using a qualitative method were excluded from the review. To assess the quality of the documents, eight questions (one score for every question) were considered about the aim, sample size, the year of publication, data collection tool, the method of the study, and publication status.

Studies that received a positive code in all questions received the highest score (eight) while the minimum score was considered five. Accordingly, the studies that obtained the minimum score were selected for the review. Finally, 37 qualified papers and two national surveys were selected with a 37079 sample size (Figure 1). In 4 studies (9-12), the sample of the research was selected from

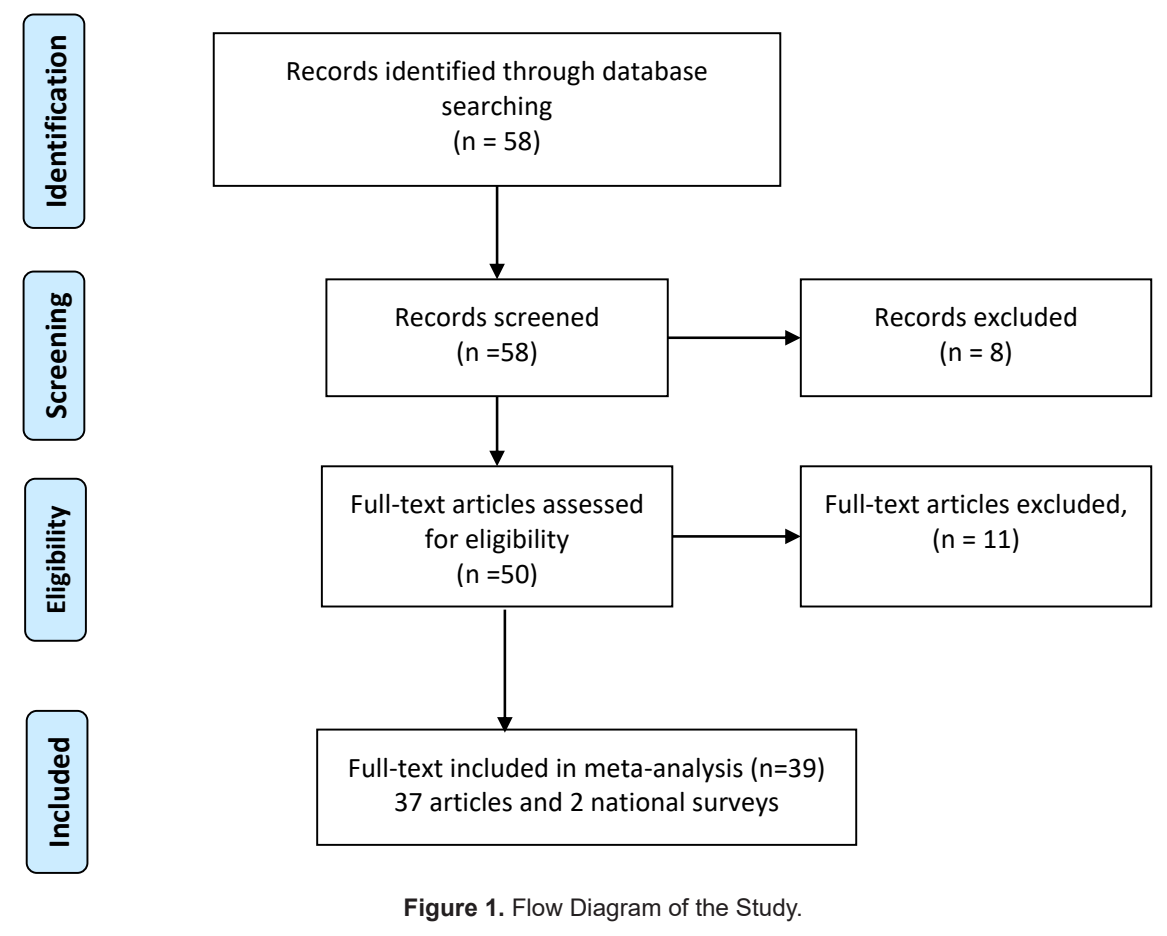


different groups or provinces. In this paper, each group or province was considered as a separate study. Thus, a total of 45 studies were selected to estimate the ideal fertility in Iran (Table 1).

The obtained data were analyzed using MedCalc 17 software. Additionally, the pooled estimates of the ideal number of children and the corresponding 95\% confidence intervals (CI) were calculated using the random effects model. In addition, statistical heterogeneity among the studies was assessed by the Cochrane Q test and $\mathrm{I}^{2}$ statistic. For the Cochrane Q test, $P<0.10$ was considered statistically significant for heterogeneity. The $I^{2}$ statistic indicates the percentage of the total variation across studies due to heterogeneity rather than chance, and can

Table 1. Description of the Studies Included in the Meta-analysis

\begin{tabular}{|c|c|c|c|c|c|c|}
\hline ID & First Author & Location of Study & Published Year & Sample & Sample Size & Mean Age \\
\hline 1 & Motlagh (15) & Iran & 2016 & Women in reproductive age, ethnic groups & 2114 & 37.6 \\
\hline 2 & Kazemipor (10) & Iran & 2014 & Married women & 6243 & 30 \\
\hline 3 & Kazemipor (10) & Iran & 2015 & Pre-marriage women & 6407 & 23 \\
\hline 4 & Firoz rad (16) & Tabriz & 2016 & Married women & 460 & 33 \\
\hline 5 & Khedive Zade (17) & Mashhad & 2013 & Women on the threshold of marriage & 450 & 22.7 \\
\hline 6 & Frotan (18) & Neka & 2016 & Ever married women & 743 & 30 \\
\hline 7 & Hosseini (19) & Oromyeh & 2009 & Kord and Turk married women & 739 & - \\
\hline 8 & Farrokh Eslamlo (20) & Oromyeh & 2013 & Pre-marriage women & 210 & 22.4 \\
\hline 9 & Mahmodian (21) & Kermanshah & 2013 & Ever married women & 200 & 24.3 \\
\hline 10 & Akaberi (22) & West Azarbayjan & 2008 & Ever married women & 1300 & 32.6 \\
\hline 11 & Yazdani (23) & Najaf Abad & 2012 & Ever married women & 100 & - \\
\hline 12 & Dorahaki (24) & NasimShahr & 2013 & Married women & 304 & 31 \\
\hline 13 & Sorosh (25) & Shiraz & 2012 & Married women & 400 & 40.82 \\
\hline 14 & Azmodeh (26) & Torbat Heydarye & 2015 & Women in childbearing age & 241 & 31.14 \\
\hline 15 & Abbasi-Shavazi (9) & Gilan & 2002 & Married women & 1277 & 33.97 \\
\hline 16 & Abbasi-Shavazi (9) & Yazd & 2002 & Married women & 1249 & 33.6 \\
\hline 17 & Abbasi-Shavazi (9) & West Azarbaijan & 2002 & Married women & 1368 & 33.88 \\
\hline 18 & Abbasi-Shavazi (9) & Sistan ... & 2002 & Married women & 1296 & 32.41 \\
\hline 19 & Askari Nadoushan (27) & Sannandaj & 2013 & Married women & 525 & 34.5 \\
\hline 20 & Bagheri (28) & Semnan & 2017 & Married women & 389 & 32.3 \\
\hline 21 & Razeghi Nasrabad (12) & Kohgiloye .. & 2013 & Married women 35-44 aged & 381 & 39.88 \\
\hline 22 & Razeghi Nasrabad (12) & Hormozgan & 2013 & Married women 35-44 & 371 & 39.71 \\
\hline 23 & Razeghi Nasrabad (12) & Semnan & 2013 & Married women 35-44 & 397 & 39.98 \\
\hline 24 & Khalaj Abadi (11) & Tehran & 2013 & One child women & 571 & 27.6 \\
\hline 25 & Kazemnejad (29) & Tehran & 2015 & Married police personal & 181 & 34 \\
\hline 26 & Saei Gharenaz (30) & Tehran & 2016 & Employed women & 200 & 37.55 \\
\hline 27 & Fallah Zade (31) & Yazd & 2013 & Ever married women aged $15-49$ years & 400 & 32.4 \\
\hline 28 & Moshfegh (32) & Tehran & 2012 & Married women & 600 & 38.6 \\
\hline 29 & Abbasi-Shavazi (33) & Yazd & 2005 & Married women & 1249 & - \\
\hline 30 & Lotfi (34) & Karaj & 2017 & Women on the threshold of marriage & 300 & 24.8 \\
\hline 31 & Abbasi-Shavazi (35) & Sannandaj & 2013 & Ever married women & 534 & 37 \\
\hline 32 & Erfani (36) & Tehran & 2009 & Married women & 1889 & - \\
\hline 33 & Chamani (37) & Tehran & 2016 & Married women & 300 & - \\
\hline 34 & Rajabi (38) & Shiraz & 2013 & Married women & 406 & 35.15 \\
\hline 35 & Sadeghi (39) & Tehran & 2016 & Mothers & 360 & - \\
\hline 36 & Hosseini 40) & Kamiaran & 2016 & Kurdish women in rural areas & 500 & 32.57 \\
\hline 37 & Hosseini (41) & Hamedan & 2014 & Married women & 273 & 31.2 \\
\hline 38 & Hosseini (42) & Mahabad & 2013 & Kurdish women & 700 & - \\
\hline 39 & Mohammadi (43) & Kerman & 2016 & Employed women & 342 & 32.26 \\
\hline 40 & Mobasheri (44) & Shahre kord & 2013 & Single child and without child women & 180 & 28.11 \\
\hline 41 & Sargolzaie (45) & Zahedan & 2015 & Married women & 160 & 26.6 \\
\hline 42 & Asadi Sarvestani (46) & shiraz & 2017 & Married women & 626 & - \\
\hline 43 & Khalaj Abadi Farahni (11) & Tehran & 2013 & Single child women & 428 & 25.2 \\
\hline 44 & Tavosi (47) & Tehran & 2016 & Married women & 600 & - \\
\hline 45 & Piltan (48) & Jahrom & 2016 & Women 25-45 aged & 176 & 33.2 \\
\hline
\end{tabular}

12 | International Journal of Women's Health and Reproduction Sciences, Vol. 8, No. 1, January 2020 
be calculated according to the following formula:

$\mathrm{I}^{2}=100 \% \mathrm{x}(\mathrm{Q}-\mathrm{df}) / \mathrm{Q} . \mathrm{Q}$ is the Cochrane statistic.

Another objective of this meta-analysis was to explore the correlation between social economic factors and the ideal fertility in studies in Iran. The degree of correlation between ideal fertility and variables was calculated using Spearman correlation coefficient, Pearson's correlation coefficient, and $r$. If the article did not report the value of the correlation coefficient $r$ directly, $r$ value was calculated based on some formulae as follows (13, $r=\sqrt{\frac{t^{2}}{t^{2}+d f}}, \quad r=\sqrt{\frac{F}{F+d f(e)}}, \quad r=\sqrt{\frac{x^{2}}{N}}$

Then, the data including the correlation coefficient, sample size, and impact direction were entered the software. The effect of the independent variable was accepted if the $P$-value was significant. Cohen presented the rules for interpreting these effect sizes, which shows that an $r$ of $0.1,0.3$, and 0.5 demonstrate small, medium, and large effect sizes, respectively (13).

\section{Results}

In this research, the mean ideal fertility in Iran was analyzed based on statistical procedures. In total, 42 studies were entered the software. According to the results (Figure 2), the mean ideal number of children in Iran is 2.2533 (95\% CI $=2.1181$ to 2.3885 ).

The result of the Shapiro-Wilk test for normal distribution showed that $P$ value is more than 0.05 , (W=0.9546, $P=0.0948$ ) and thus the hypothesis is accepted regarding the normality of the distribution of the observations in the sample.

In addition, the pooled mean ideal fertility by the random effect is 2.253 (95\% CI: 2.233 to 2.274 ). The results of the Cochran test and $\mathrm{I}^{2}$ statistics represented significant heterogeneity for the prevalence of the ideal number of children $(\mathrm{Q}=1722.0911, \mathrm{df}=41, P<0.0001$, and

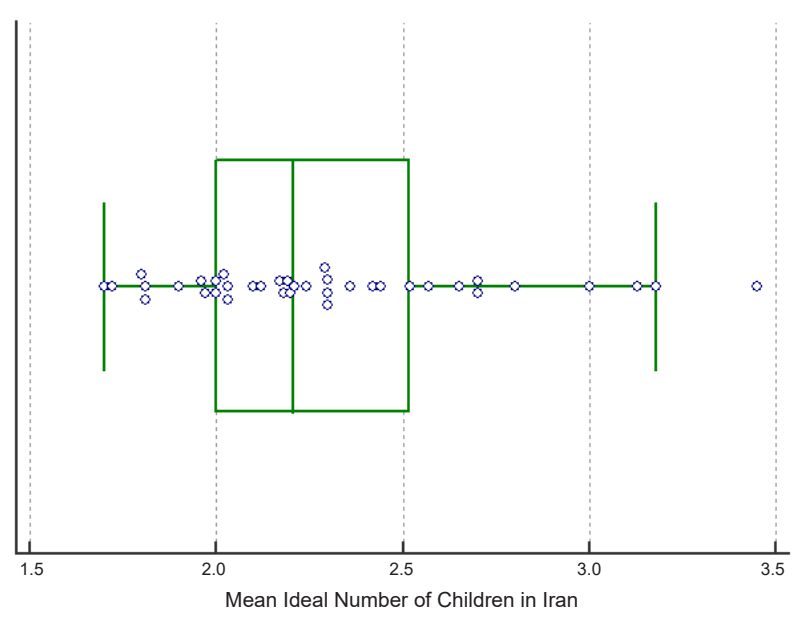

Figure 2. Estimation of the Mean Ideal Number of Children in Iran.
$\left.I^{2}=97.62 \%\right)$. As shown in Figure 3, among the included studies, the highest value for ideal fertility belongs to the study by Abbasi Shavazi et al (9) with 3.4 children in Sistan and Baluchestan while the lowest value (1.32) is related to the study by Mohammadi and Seifori (43) conducted among employed women in Kerman.

In addition to the estimation of the mean ideal number of children, this meta-analysis was implemented to estimate a fairly accurate level of childlessness, one child, two children, and three children and more as the ideal number of children in Iran. In this session, 34 studies with a 32300 sample size were entered the software. The results are shown in Table 3 and Figures 4-7. The results of Cochran's Q test and $\mathrm{I}^{2}$ statistics demonstrated considerable heterogeneity among the included studies for childlessness $\left(\mathrm{Q}=1000.5125, P<0.001\right.$, and $\left.\mathrm{I}^{2}=96.70 \%\right)$, 1 child $\left(\mathrm{Q}=2620.0202, P<0.001\right.$, and $\left.\mathrm{I}^{2}=98.74 \%\right), 2$ children $\left(\mathrm{Q}=1749.7591, \quad P<0.001\right.$, and $\left.\mathrm{I}^{2}=98.11 \%\right)$, and 3 children and more $(\mathrm{Q}=5016.5475, P<0.001$, and $\left.\mathrm{I}^{2}=99.34 \%\right)$.

According to the random effects model, the proportions of childlessness, one child, two children, and three children and more as the ideal number of children were $0.83,15.99$, 56.092, and 22.26, respectively.

As shown, the highest prevalence of childlessness as ideal fertility was reported by Asadi Sarvestani et al (46) in Shiraz (15.81\%) and Mohammadi and Seifori (43) in Kerman (11.1\%), respectively.

In addition, the highest prevalence of one child as ideal fertility was reported by Saei Gharenaz et al. (30) in Tehran (57\%) and Mohammadi and Seifori (43) in Kerman (45.90\%). Most of the studies revealed a considerable gap between actual fertility and ideal fertility in Iran. For example, according to the study of Kazemipour (10) conducted under the auspices of the Statistical Centre of Iran, the mean actual number of children among married

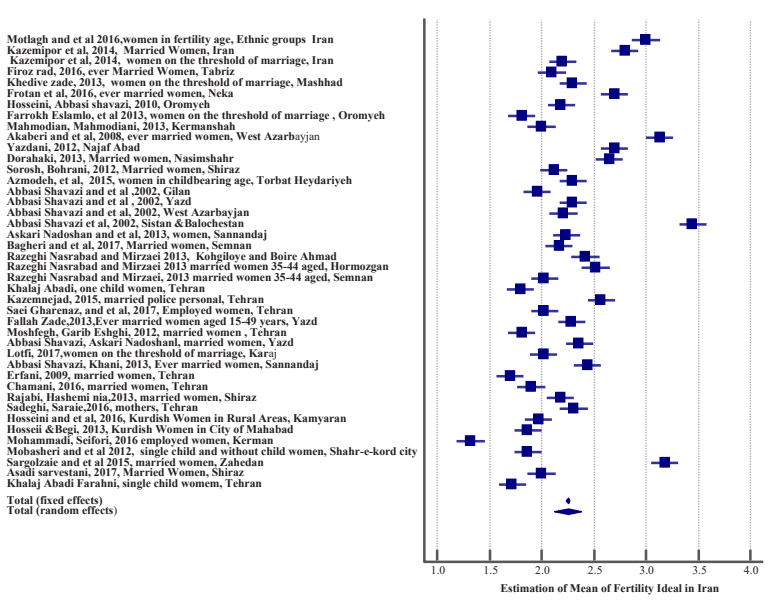

Figure 3. Meta-analysis of the Estimation of Mean Fertility Ideal in Iran Note. Total (fixed effects) $=2.25$ (2.233 to 2.274), Total (Random effects) $=2.25$ (95\% Cl 2.122 to 2.385$)$, Test for heterogeneity: $\mathrm{Q}=1722.0911, d f$ $=41$, Significance level $P<0.0001 ; \mathrm{I}^{2}$ (inconsistency) $=97.62 \%, 95 \% \mathrm{Cl}$ for $\mathrm{I}^{2}=97.24$ to 97.95 . 


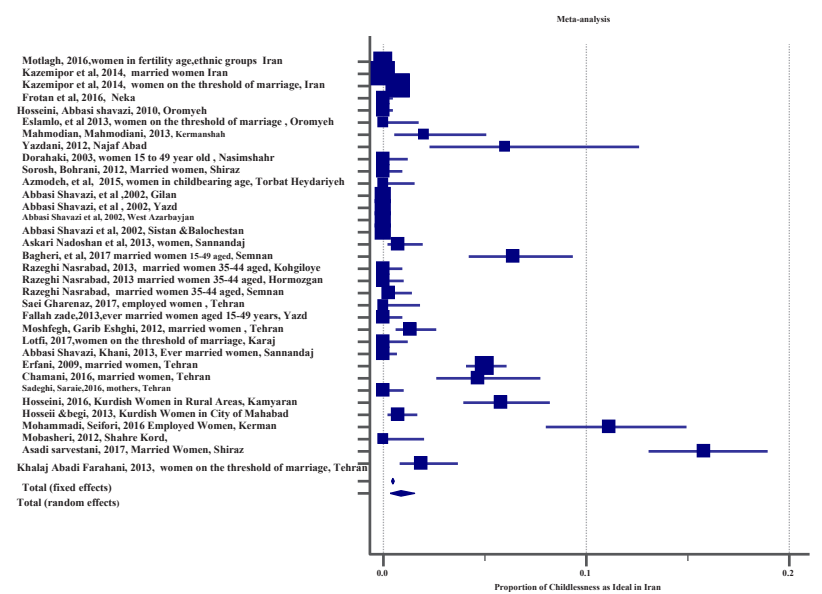

Figure 4. Meta-analysis of the Proportion of Childlessness as Ideal Fertility in Iran.

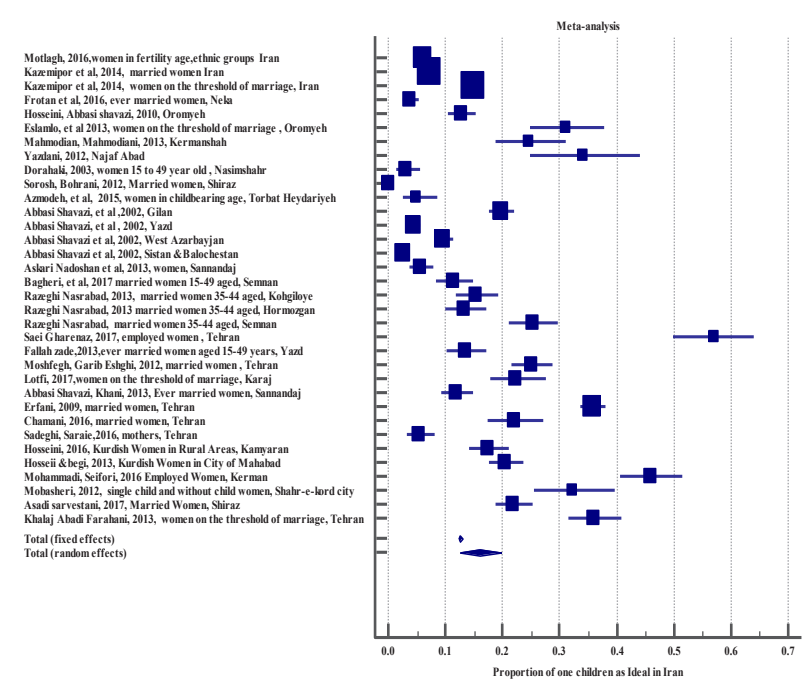

Figure 5. Meta-analysis of the Proportion of 1 Child as Ideal Fertility in Iran.

women aged 15-49 was 1.7 , but the mean ideal number of children was 2.8 children. Despite the differences in the actual fertility level in various regions of the country, the predominant pattern in the number of desired children is two children.

Table 2 presents the results for the subgroup analysis based on the correlation coefficient value between ideal fertility and explanatory variables. Any study showing the correlation coefficients between ideal fertility and the other variable was eligible. The criterion for testing the hypotheses in the meta-analysis was their repetition in at least five studies, therefore, hypotheses with less than five repetitions were deleted and the rest entered the software $(49,50)$.

To enter the data in the software, all the statistics were first converted to the correlation coefficient through the corresponding formulas due to the variety of used methods and the variety of statistics. Then, the transformed statistical scores were pooled and back-transformed to the

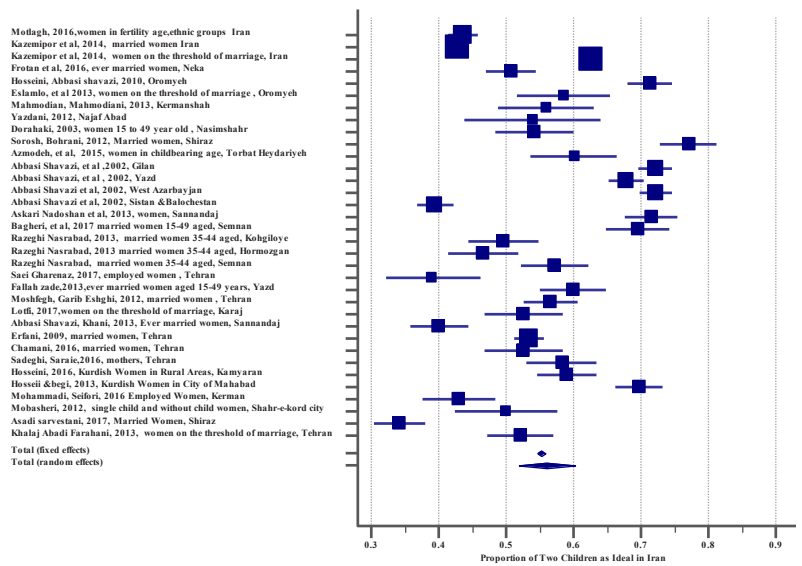

Figure 6. Meta-analysis of the Proportion of 2 Children as Ideal Fertility in Iran
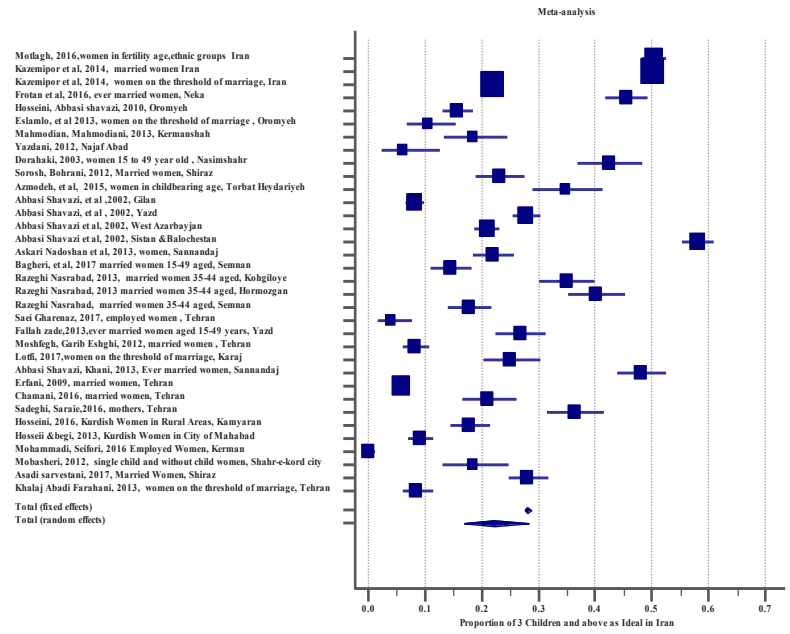

Figure 7. Meta-analysis of the Proportion of 3 Children and More as Ideal Fertility in Iran.

pooled correlation coefficients.

The correlations of deal fertility with the education level and residence were frequently studied $(n=10$; pooled correlation coefficient $=-0.131 \& 0.130$ ). The results of the heterogeneity test for education, the value of children, gender preference, age, income, and the place of residence were significant. Therefore, the random model was preferred over the fixed model. The fixed model is preferable considering the $P$ value of the actual number of children, the employment status, and the economic costs of the children. According to the $P$-value of the model, the influence of other independent variables on the ideal number of the children is accepted except for the residence place. Based on the level of pooled correlation coefficients, the age, actual fertility, and economic cost may be among the most important predictor variables as the ideal fertility and the effect size of age on the mean ideal fertility is moderate. The effect size of other variables is at a low level. 
Table 2. Results for the Subgroup Analysis Based on Correlation Coefficient Value Between Ideal Fertility and Variables

\begin{tabular}{|c|c|c|c|c|c|c|c|c|c|}
\hline Correlation & Education & $\begin{array}{c}\text { Actual } \\
\text { Fertility }\end{array}$ & $\begin{array}{c}\text { Economic } \\
\text { Cost }\end{array}$ & $\begin{array}{c}\text { Gender } \\
\text { Preference }\end{array}$ & Employment & Age & Income & $\begin{array}{l}\text { Value of } \\
\text { Children }\end{array}$ & $\begin{array}{l}\text { Residence } \\
\text { Place }\end{array}$ \\
\hline Fixed model & -0.129 & 0.273 & -0.225 & 0.0749 & 0.0453 & 0.307 & -0.142 & 0.140 & 0.130 \\
\hline $95 \% \mathrm{Cl}$ & $\begin{array}{l}-0.159 \text { to } \\
-0.1000\end{array}$ & $\begin{array}{c}0.241 \text { to } \\
0.305\end{array}$ & $\begin{array}{c}-0.193 \text { to } \\
0.258\end{array}$ & $\begin{array}{c}0.0394 \text { to } \\
0.110\end{array}$ & $\begin{array}{c}0.0124 \text { to } \\
0.0781\end{array}$ & $\begin{array}{c}0.273 \text { to } \\
0.341\end{array}$ & $\begin{array}{c}-0.175 \text { to } \\
-0.108\end{array}$ & $\begin{array}{c}0.173 \text { to } \\
-0.106\end{array}$ & $\begin{array}{c}0.101 \text { to } \\
0.159\end{array}$ \\
\hline$Z$ value & -8.551 & 15.891 & -13.148 & 4.135 & 2.697 & 16.493 & -8.139 & 8.098 & 8.587 \\
\hline$P$ value & 0.001 & 0.001 & 0.001 & 0.001 & 0.007 & 0.001 & 0.001 & 0.001 & 0.001 \\
\hline Random model & -0.131 & 0.248 & -0.236 & 0.0780 & 0.0494 & 0.311 & -0.154 & 0.111 & 0.130 \\
\hline $95 \% \mathrm{Cl}$ & $\begin{array}{l}-0.221 \text { to } \\
-0.0395\end{array}$ & $\begin{array}{c}-0.0279 \text { to } \\
0.489\end{array}$ & $\begin{array}{c}-0.153 \text { to } \\
0.315\end{array}$ & $\begin{array}{c}0.0177 \text { to } \\
0.138\end{array}$ & $\begin{array}{c}-0.0187 \text { to } \\
0.117\end{array}$ & $\begin{array}{c}0.0844 \text { to } \\
0.507\end{array}$ & $\begin{array}{l}-0.256 \text { to } \\
-0.0486\end{array}$ & $\begin{array}{c}0.306 \text { to } \\
0.0921\end{array}$ & $\begin{array}{c}0.0919 \text { to } \\
0.168\end{array}$ \\
\hline$Z$ value & -2.798 & 1.765 & -5.468 & 2.535 & 1.422 & 2.660 & -2.854 & 1.073 & 6.627 \\
\hline$P$ value & 0.005 & 0.077 & 0.001 & 0.011 & 0.155 & 0.008 & 0.004 & 0.283 & 0.001 \\
\hline \multicolumn{10}{|c|}{ Test for heterogeneity } \\
\hline$Q$ & 95.3067 & 304.3600 & 43.9286 & 19.1955 & 34.1364 & 236.2583 & 66.6614 & 248.9654 & 16.4187 \\
\hline $\mathrm{df}$ & 10 & 5 & 7 & 7 & 8 & 6 & 7 & 7 & 10 \\
\hline$P$ value & 0.0001 & 0.0001 & 0.0001 & 0.0076 & 0.0001 & 0.0001 & 0.0001 & 0.0001 & 0.0883 \\
\hline $\mathrm{I}^{2}$ (inconsistency) & $89.51 \%$ & 98.36 & $84.07 \%$ & $63.53 \%$ & $76.56 \%$ & $97.46 \%$ & $89.50 \%$ & $97.19 \%$ & $39.09 \%$ \\
\hline
\end{tabular}

Note. $\mathrm{Cl}$ : Confidence interval; df; degree of freedom.

\section{Discussion}

In general, it is highly important to estimate the mean ideal fertility and prevalence of childlessness and one child as ideal fertility in Iran. Ideal fertility can provide convenient approaches to prevent a decline in fertility, and nowadays, it is an important issue for demographers and policymakers. According to our knowledge, this is the first systematic review and meta-analysis of ideal fertility in Iran. The review of the latest research has confirmed that a noticeable ideational change has occurred in marriage, childbearing, fertility behavior, and the ideals of women. Based on the results, the geometric mean ideal fertility was 2.25 (95\% $\mathrm{CI}=2.1181$ to 2.3885$)$ and the median was $2.19(95 \% \mathrm{CI}=2.0300$ to 2.3000$)$. The pooled mean ideal fertility by random effect was also $2.25(95 \% \mathrm{CI}=2.122$ to 2.385). The results of the Cochran test and $\mathrm{I}^{2}$ statistics showed substantial heterogeneity for the prevalence of the ideal number of children.

The proportions of childlessness, one child, two children, and three children and more as the ideal number of children were $0.83,15.99,56.092$, and 22.26 , respectively. Despite the differences in the actual fertility level in various regions of the country, the predominant pattern in the number of desired children was two children. These results imply a convergence in fertility ideals in Iran. It is also worth noting that even those with many children considered two children as the ideal number of children for a family. These facts indicate the diffusion of low fertility values and norms and convergence in the fertility behavior and ideals of Iranian women. This result is consistent with the findings of Abbasi Shavazi (9), which demonstrated the convergence of fertility behaviors and ideals toward two children in Iran.

The results of this meta-analysis showed that the highest value of mean ideal fertility belongs to the study by Abbasi-Shavazi et al (9) with 3.4 children in Sistan and Balochestan. According to this study, only 40 to $45 \%$ of each marriage cohort considered two children as ideal while $40 \%$ believed that 4 children or more would be ideal for a couple. Even for the most recent marriage cohort, fertility preferences in Sistan and Baluchestan remain considerably higher than the other three provinces (Gilan, Yazd and West Azarbaijan), suggesting that the higher fertility in that province is likely to remain evident for some time.

The mean effect size indicated the moderate effect size of age on the mean ideal fertility. Although in the most recent birth cohort, fertility ideal was considerably lower than the other cohort, norms against large families (four children and more) were reinforced in all birth cohorts. The results of the present study are in line with the findings obtained by the following studies.

For instance, Hosseini and Abbasi Shavazi (19) concluded that the two-child norm and declining tendencies toward big families are in accord with the assessment of the benefit and cost associated with having children.

Furthermore, based on the studies conducted by Razeghi Nasrabad and Saraei (51), the older cohort who themselves had very high fertility also supported the small size of the family. This confirms that there was an extensive ideational change in the small family size norms.

The results revealed that only $0.8 \%$ of Iranian women considered childlessness as an ideal reproductive dimension. These findings also corroborate with those of other studies. Razeghi Nasrabad et al (52) used data from 2011 Iran Demographic and Health Survey, as well as the 1996 and 2011 censuses and estimated the level 
of childlessness in Iran and found that voluntary and involuntary childlessness were 10.1 and $3.6 \%$, respectively in 2011. However, their results demonstrated that Iranian women are progressively likely to plan children and $0.3 \%$ of them had no intention for childbearing in the future.

The proportion of one child as the fertility ideal was 15.99. This is relatively high and its trend is also increasing and may have implications for the future of fertility in Iran. Khalajabadi Farahani (11) investigated the intention for one child and its determinants among men and women in Tehran. The results showed that the intention for a single child among men was 1.79 times more than women. Concurrently, the intention for a single child significantly increased among both men and women with an increase in the level of education, individualism, and the lack of religious adherence. Among men, unemployment increases the intention for a single child more than seven times. Razeghi Nasrabad et al (58) reported that the one-child survival of the couples is the result of delayed marriage and childbearing, avoiding dangers and social harm, feeling the lack of family and social support, the difficulty of balancing work and family, as well as the attitudinal changes in the values and goals of childbearing.

Moreover, pooled correlation coefficients showed that the economic cost of children is an important predictor variable for the ideal fertility. In eight studies, the ideal fertility was linked to a high economic cost of children, unfavorable economic conditions, along with job and economic insecurity $(12,35,58)$.

The correlations between fertility ideal and education level were studied frequently. In several studies, improvement in women's educational attainment was known as an effective factor in low fertility ideal in Iran. In addition, 11 studies reported the value of correlation coefficient $r$ directly or indirectly. Additionally, the pooled correlation coefficient confirmed this correlation and the effect size was at a low level.

In nine studies, the ideal fertility was associated with women's employment and women's aspiration for paid work $(23,33,46)$. Pooled correlation coefficients between women's employment and ideal fertility were confirmed as well. This can be greatly related to the high conflict between work and family $(23,54)$.

In summary, from the review literature in Iran, the main causes of low fertility ideal can be deduced to factors such as improvement in women's educational attainment (19), women's aspiration for paid work (43), the high economic cost of children, unfavorable economic conditions, job and economic insecurity (38), the conflict between work and family $(23,58)$, and less normative pressure for having more children $(12,36,40)$.

These are serious obstacles for policymakers who pursue policies for increasing population growth. On the other hand, the high prevalence of marriage, little preference toward zero parity, religious and cultural norms, and the emotional value of children are the characteristics of the
Iranian family. Fertility is maintained at the replacement level if desirable conditions for childbearing are provided for young couples. The pooled mean ideal fertility by random effect was also 2.25 .

Although most Iranian couples want two children, a significant percentage of couples are single-child or childless. According to previous research $(52,59)$, an increase in childlessness and one-child family in Iran is partly due to tempo effects related to delaying marriage and childbearing.

Delaying childbearing can be risky. More precisely, fecundity decreases with age $(53,54)$. The limitation of biological time to fertility or the "biological clock" is one of the main constraints of women in this regard. According to Morgan and Hagewen (59) and Schröder-Butterfill and Kreager (60), among women who used no contraception, the percent of women who remain childless varies by age at marriage and childbearing, namely, $2 \%, 10 \%, 15 \%, 60 \%$, and $100 \%$ for women married at the age of 15-19, 25-29, $30-34,40-44$, and 45-49, respectively. However, women's knowledge regarding fertility, infertility risk factors, and the consequences of the postponement of childbearing may be low (55-57). Thus, it is important that medical professionals educate young couples and work to raise their awareness about the effects of aging on fertility and pregnancy, along with the biological clock for childbearing and reproductive outcomes in later life since these factors are essential for improving the reproductive health of women.

This meta-analysis study failed to include numerous studies that reported no correlation coefficients or could not be calculated based on some statistics. This might have had some effects on the results of our study.

\section{Conflict of Interests}

Authors declare that they have no conflict of interests.

\section{Ethical Issues}

Not applicable.

\section{Financial Support}

This paper is based on a research project titled "A Systematic Review of low fertility in Iran" which was supported by National Population Studies \& Comprehensive Management Institute, Tehran, Iran. Approval number is $21 / 20400$.

\section{References}

1. Abbasi-Shavazi MJ, Hosseini-Chavoshi M. The Fertility Transition in Iran in Last Four Decades. Tehran: Statistical Center of Iran; 2013. [Persian].

2. Abbasi-Shavazi MJ, McDonald P, Hosseini-Chavoshi M. The Fertility Transition in Iran: Revolution and Reproduction. Dordrecht Heidelberg: Springer; 2009.

3. Zaidi B, Morgan SP. The second demographic transition theory: a review and appraisal. Annu Rev Sociol. 
2017;43:473-492. doi:10.1146/annurev-soc-060116-053442

4. Ibisomi L, Gyimah S, Muindi K, Adjei J. Ideal versus actual: the contradiction in number of children born to Nigerian women. J Biosoc Sci. 2011;43(2):233-245. doi:10.1017/ S0021932010000684

5. Günther I, Harttgen K. Desired fertility and number of children born across time and space. Demography. 2016;53(1):55-83. doi:10.1007/s13524-015-0451-9

6. Hagewen KJ, Morgan SP. Intended and ideal family size in the United States, 1970-2002. Popul Dev Rev. 2005;31(3):507-527. doi:10.1111/j.1728-4457.2005.00081.x

7. Moosazadeh M, Nekoei-Moghadam M, Emrani Z, Amiresmaili M. Prevalence of unwanted pregnancy in Iran: a systematic review and meta-analysis. Int J Health Plann Manage. 2014;29(3):e277-290. doi:10.1002/hpm.2184

8. Hajarizadeh B, Sadeghirad B, Haghdoost A, Mirzazadeh A. The application of systematic review and meta-analysis concepts in summarizing the findings of observational studies. Iran J Psychiatry. 2007;2(4):132-136.

9. Abbasi-Shavazi MJ, Hosseini-Chavoshi M, McDonald P, Delavar B. Fertility Transition in Iran: Evidence from Four Selected Provinces. Tehran: Iran Ministry of Health and Medical Education; 2004. [Persian].

10. Kazemipour SH. Childbearing Attitudes and its socio economic and cultural factors. Tehran, Iran: Statistical Research Center; 2014. [Persian].

11. Khalajabadi Farahani F. Norms, Intention and Behavior of married women and men resided in Tehran towards having single-child and its socio-cultural determinants, Final Report. Iran: Population Studies and Research Institute in Asia and the Pacific, Ministry of Science, Research and Technology; 2012. [Persian].

12. Razeghi-Nasrabad HB, Mirzaei M. Gap between ideal number of children and actual number of children in selective provinces. Journal of Population Association of Iran. 2012;7(13):149-176. [Persian].

13. Iman $M$, Khaje Nori B. Meta-analysis, a method for studying studies. Hawzah and University, 2006;12(49):83120. [Persian].

14. Haidar Ali H. Handbook on Meta-analysis in Scientific Research. Tehran: Samt; 2012. [Persian].

15. Motlagh ME, Taheri M, Eslami M, Nasrollapour Shirvani SD. Factors affecting the fertility preferences in Iranian ethnic groups. Journal of Urmia Nursing and Midwifery Faculty. 2016;14(6):485-495. [Persian].

16. Rad F, Savabi H. Investigation on tendency to fertility and its related social factors (a case study of married women aged 15 to 50 in Tabriz). Journal of Woman and Family Studies. 2015;3(1):127-155. [Persian].

17. Khadivzadeh T, Arghavani E, Shakeri MT. Attitude toward governmental incentives on childbearing and its relationship with fertility preferences in couples attending premarital counseling clinic in health centers in Mashhad. Journal of Mazandaran University of Medical Sciences. 2015;24(120):1-13. [Persian].

18. Foroutan Y, Saeidimadani SM, Askarinadooshan A, Ashkaran R. Gender Preferences in Neka, Mazandaran Province: Patterns and Determinants. Journal of Population Association of Iran. 2014;9(17):171-197. [Persian].

19. Hosseini H, Abbasi-Shavazi MJ. Ideational changes and its impact on fertility behavior and attitudes of Kurd and
Turk women. Womens Research Journal. 2009;7(2):55-84. [Persian].

20. Farrokh-Eslamlou H, Vahabzadeh Z, Moeini SR, Moghaddam Tabrizi F. Pre-marriage couplesfertility attitude following recent childbearing persuasive policies in Iran. Journal of Urmia Nursing and Midwifery Faculty. 2013;11(10):836-846. [Persian].

21. Mahmoudian H, Mahmoudiani S. A comparative study of the attitudes of men and women towards the desired number of children: a case study of individuals attended for the pre-marriage medical test in Kermanshah city. Women's Strategic Studies. 2014;63(16):97-124. [Persian].

22. Akaberi A, Mahmoudi M, Zeraati H, Majlesi F. Study of the relationship of socioeconomic and demographic factors with fertility. Journal of Sabzevar University of Medical Sciences. 2008;15(1):40-45. [Persian].

23. Yazdani F. Comparison of the some factors in women with unwanted and planned pregnancy. Family Health. 2012;1(2):19-26. [Persian].

24. Dorahaki, A. Determinants of women's ideal fertility: study of women 15 to 49 year old in Nasimshar city in 2015. Razi Journal of Medical Sciences. 2016;22(141):59-69. [Persian].

25. Soroush M, Bahrani S. The association between religiosity, attitudes to gender roles and attitudes towards children with actual and ideal number of children. Journal of Women in Development Policy. 2013;11(2):189-208. [Persian].

26. Azmoude E, Barati-Far S, Behnam H, Aradmehr M. Relationship between Gender Preference, Birth Interval and Sex Composition on Fertility Behavior. Journal of Torbat Heydariyeh University of Medical Sciences. 2015;3(3):1518. [Persian].

27. Askari-Nodoushan A, Hosseini H, Karimi H. A Comparative Study of the Determinants of Fertility Ideals Among Employed and Unemployed Kurdish Women in the Sanandaj. Women's Strategic Studies. 2015;17(67):45-83. [Persian].

28. Bagheri A, Razeghi-Nasrabad HB, Saadati M. Identification of Fertility Preference Determinants Using Poisson Regression. Iranian Journal of Epidemiology. 2017;13(2):153-161. [Persian].

29. Kazemnejad A, Gholami-Fesharaki M, Samadi S, Gilani N. Determining the Factors Affecting Childbearing Tendency in Tehran Police Personnel. Journal of Police Medicine. 2015;4(3):201-208. [Persian].

30. Saei Gharenaz M, Ozgoli G, Hajizadeh F, Sheikhan Z, Nasiri M, Jannesari Sh. The relationship between religious orientation with intention of desired fertility and actual and desirable number of children in working women of Tehran, Iran. Journal of Research on Religion \& Health. 2017;3(1):79- 90. [Persian].

31. Fallahzadeh H, Farajpour Z, Emam Z. Duration and determinants of birth interval in Yazd, Iran: a population study. Iran J Reprod Med. 2013;11(5):379-384.

32. Moshfegh M, Gharib Eshgi S, An analysis on relationship between the value of children and fertility among tehran's women. Women's Strategic Studies. 2013;15(58):93-120. [Persian].

33. Abbasi-Shavazi MJ, Askari-Nodoushan A. Family changes and fertility decline in Iran: case study in Yazd province. Journal of Social Sciences. 2005;25:25-76. [Persian].

34. Lotfi R, Rajabi Naeeni MRN, Rezaei N, Farid M, Tizvir 
A. Desired numbers of children, fertility preferences and related factors among couples who referred to pre-marriage counseling in Alborz province, Iran. Int J Fertil Steril. 2017;11(3):211-219. doi:10.22074/ijfs.2017.5010

35. Abbasi-Shavazi MJ, Khani S. Economic insecurity and fertility: case study of married women in Sanandaj district. Journal of Population Association of Iran. 2016;9(17):3776. [Persian].

36. Erfani A, Shojaei J. Living conditions and ideal number of children in Tehran, Iran. Payesh. 2018;17(3):307-314. [Persian].

37. Chamani S, Shekarbeigi A, Moshfegh M. Sociological Determinants of Fertility (Case Study: Married Women Living in Tehran). The Socio Cultural Strategy Journal. 2016;5(20):137-165. [Persian].

38. Rajabi M, Hasheminya F. Value of children and fertility in the city of Shiraz. Journal of Population Association of Iran. 2013;8(15):23-42. [Persian].

39. Sadeghi HS, Saraie H. Effective Factors on Mothers' Inclination to Have Children in Tehran. Social Development and Welfare Planning. 2016;7(27):1-32. [Persian].

40. Hosseini H, Askari-Nodoushan A, Moradi N. A Comparative Study of Childbearing Desires of Shia and Sunni Kurdish Women in Rural Areas of Kamyaran. Journal of Women and Family Studies. 2016;4(1):63-84. [Persian].

41. Hosseini H, Bagi B. Socioeconomic, cultural and demographic determinants of childbearing desires among married women attending health centers in Hamedan (2012). Journal of Kermanshah University of Medical Sciences. 2014;18(1):35-43. doi:10.22110/jkums.v18i1.1578

42. Hosseini H, Bagi B. Women's autonomy and fertility ideals among Kurdish women in the city of Mahabad. Women in Development and Politics. 2013;10(4):57-78. [Persian].

43. Mohammadi N, Seifori B. Sociological Study on women's fertility preferences among working women. Women Families Cultural Educational Quarterly. 2016;11(36):4970. [Persian].

44. Mobasheri M, Alidosti M, Sorshajani S, Khosravi F, Khalafian P, Jalilian M. Determination of the most important factors influencing the fertility patterns of single child and without child families in Shahr-e-kord city in 2013. Journal of Ilam University of Medical Sciences. 2013;21(6):63-70. [Persian].

45. Sargolzaie N, Kiani M, Dehghan Haghighi J, Sargazi S. Determinants of Fertility Patterns in Zahedan, Southeast Iran, 2015. Health Scope. 2016;6(3):e15117. doi:10.5812/ jhealthscope. 15117

46. Asadi Sarvestani KH, Leng Khoo S, Malek NM, Mat Yasin SM, Ahmadi A. Factors Influencing the Desired Number of Children Among Married Women in the Reproductive Age and its Implications for Policy Making, Women Health Bull. 2017;4(2):e38928. doi:10.17795/whb-38928

47. Tavousi M, Motlagh ME, Eslami M, Haerimehrizi A,
Hashemi A, Montazeri A. Fertility desire and its correlates: a pilot study among married citizens living in Tehran, Iran. Payesh. 2015;14(5):597-605. [Persian].

48. Piltan F, Rahmanian M. Investigating factors affecting the tendency toward childbearing among married men and women (case of study: men and women aged 25 to 45 years old in Jahrom). Journal of Iranian Social Development Studies. 2015;7(2):121-134. [Persian].

49. Zkia M, Tavakoli M. Meta-Analysis of Job satisfaction in Educational Organizations. Nameh-ye Olum-e Ejtemai. 2006(27):1-26. [Persian].

50. Thompson S. Controversies in meta-analysis: the case of the trials of serum cholesterol reduction. Stat Methods Med Res. 1993;2(2):173-192. doi:10.1177/096228029300200205

51. Razeghi-Nasrabad HB, Saraei H. A Cohort Analysis of Women's Attitude towards Value of Children in Semnan Province. Women in Development \& Politics. 2014;12(2):229-250. doi:10.22059/jwdp.2014.52357

52. Razeghi-Nasrabad HB, Abbasi-Shavazi MJ, Moeinifar M. Are we facing a dramatic increase in infertility and involuntary childlessness that lead to lower fertility? Crescent J Med Biol Sci. 2020;7(2):1-14.

53. Dunson DB, Baird DD, Colombo B. Increased infertility with age in men and women. Obstet Gynecol. 2004;103(1):5156. doi:10.1097/01.aog.0000100153.24061.45

54. Rowe T. Fertility and a woman's age. J Reprod Med. 2006;51(3):157-163.

55. Jensen RE, Martins N, Parks MM. Public perception of female fertility: initial fertility, peak fertility, and agerelated infertility among US adults. Arch Sex Behav. 2018;47(5):1507-1516. doi:10.1007/s10508-018-1197-4

56. Daniluk JC, Koert E, Cheung A. Childless women's knowledge of fertility and assisted human reproduction: identifying the gaps. Fertil Steril. 2012;97(2):420-426. doi:10.1016/j.fertnstert.2011.11.046

57. Deatsman S, Vasilopoulos T, Rhoton-Vlasak A. Age and fertility: a study on patient awareness. JBRA Assist Reprod. 2016;20(3):99-106. doi:10.5935/1518-0557.20160024

58. Razeghi Nasrabad H, Hosseini Z, Sheykhi M. Women's lived experience of one- child with Emphasis on the Reasons and Consequences in the City of Sharyar. Journal of Population Aassosiation of Iran. 2018;11(22):43-82. [Persian].

59. Morgan SP, Hagewen K. Is Very Low Fertility Inevitable in America? Insights and Forecasts from an Integrative Model of Fertility. In: Booth A, Crouter AC, eds. The New Population Problem: Why Families in Developed Countries Are Shrinking and What It Means. Mahwah, NJ: Lawrence Erlbaum Associates; 2005:3-28.

60. Schröder-Butterfill E, Kreager P. Actual and de facto childlessness in old age: evidence and implications from East Java, Indonesia. Popul Dev Rev. 2005;31(1):19-55. doi:10.1111/j.1728-4457.2005.00051.x

(c) 2020 The Author (s); This is an open-access article distributed under the terms of the Creative Commons Attribution License (http://creativecommons.org/licenses/by/4.0), which permits unrestricted use, distribution, and reproduction in any medium, provided the original work is properly cited. 